\title{
Lei geral de aplicação das normas jurídicas *.
}

\author{
Haroldo Valladão. \\ Catedrático de Direito Internacional Privado \\ na Faculdade Nacional de Direito.
}

\section{Método e orientação geral.}

O método que adotei no Anteprojeto para a formulação dos textos foi o de estabelecer soluções justas, eqüitativas e brasileiras, acompanhando os grandes progressos contemporâneos, com a diretriz de meus trabalhos jurídicos, de democratização, humanização e socialização do direito a fim de que êste atenda ao interêsse de todos e não ao de alguns ou de pequenos grupos, ampliando-se, cada vez mais, para proteger os fracos, os humildes, os que ainda estão na periferia de nossa ordem jurídica (H. Valladão, Democratizacão e Socialização do Direito Internacional, 1961 em português e 1962 em francês, Desenvolvimento Econômico e Social em Forma Jurídica, 1962 e Aos Juristas do Desenvolvimento, 1963).

Destarte a minha preocupação não foi a de estabelecer regras absolutas, de extremo rigor lógico, que podem ser muito elegantes mas levam, tantas vêzes, a resultados inícuos, desumanos.

Para cada problema procuro, desde logo, tomar seus pontos cardeais: verticalmente, vejo as soluções apresentadas através da história, em especial do direito pátrio, horizontalmente, considero, no plano do direito comparado, as

* O autor dêste artigo elaborou o Anteprojeto Oficial de Reforma da Lei de Introdução do Código Civil. 
medidas adotadas noutros países pelos estrangeiros que são nossos pósteros no espaço, superiormente, procuro a funda-mentação filosófica, moral, e mesmo jusnaturalística, e, realisticamente, levo em conta as experiências que todos. encontramos nas decisões dos tribunais, na jurisprudência que é a tábua de logarítimos dos juristas e, também na prática do povo e das autoridades, e, ainda nos fatôres sociais. e econômicos.

Em coroamento final atendo ao espírito democrático. pelo qual a lei não é feita no interêsse dos seus autores ou aplicadores mas para a felicidade do povo que a vai observar.

Feita a opção, adotada a norma, a redação exige numerosas e sucessivas fórmulas, e, de regra, se mantenho o princípio, conservo a mesma redação, evito sempre criarnovas expressões para dizer as mesmas coisas por uma questão de originalidade ou de gôsto literário. Seria criar problemas de instabilidade jurídico-social, com dúvidas de interpretação, a exigir, quem sabe, para devida compreen-são um vocabulário preliminar à lei, segundo fazem diplomas inglêses e norte-americanos.

Um Código ou uma lei não pode ser um tratado integral de lógica ou de ciência jurídica. Constitui um guia, um roteiro para o povo e as autoridades na estrada da justiça, fundado na experiência, orientado pelo progresso, apontando marcos e encruzilhadas da planície, mas, também, salientando pontes, túneis e precipícios e, mesmo avisando das curvas e desvios necessários.

E dai textos que representam simples compromissos, preceitos incapazes de ser generalizados, soluções que precisam ser incompletas e omissões que devem permanecer, pois a opção ainda não pôde ser definitiva e há de ser deixada à jurisprudência e à prática, mais próximas da vida.

Consagrei à feitura da presente Lei Geral um ano de trabalhos e, principalmente, em dias e horas retirados do. tempo que deveria repousar pois não deixei de dar minhas. 
aulas na Faculdade Nacional de Direito da Universidade do Brasil, na Faculdade de Direito da PUC e no Instituto Rio Branco, e de exercer as funções do cargo de Consultor Jurídico do Ministério das Relações Exteriores.

Realisei-o no mesmo propósito de servir, desinteressadamente, ao Brasil, sem aceitar qualquer remuneração, com que o saudoso Ministro Alfredo Valladão organizou os Projetos de Código das Águas de 1907 e de 1933, e com que projetei em 1933 as Leis de Entrada e Expulsão de estrangeiros, Naturalização e Cooperação Internacional nos Processos Criminais (Extradição), como Relator da 15. ${ }^{a}$ SubComissão Legislativa (Dec. 19459, de 6/12/1930, art. $1 .^{\circ}, \S 3 .^{\circ}$ ).

$\mathrm{O}$ anteprojeto considerou as tradições brasileiras, o direito reinicola, imperial e republicano até os nossos dias, e no direito comparado, Códigos e leis de todos os principais países, atualizados, até os mais recentes, pós-guerra, do Egito, 1948, Síria, 1949, Filipinas, 1951, da Etiópia, organizado por professôres da Faculdade de Direito de Paris, 1960, Bases da Legislação Civil Russa, 1960, Projeto francês de 1950 e Projetos de Leis de Direito Internacional Privado, de Portugal, 1951, da Polônia, 1961 e da Venezuela, 1963.

Entre as principais inovações da Lei Geral que é profundamente democrática destacam-se a publicação imediata das leis pela ordem da promulgação; a sua ampla distribuição em avulsos no Brasil e no exterior; a sua vigência também na plataforma continental; a sua revogação por fôrça de costume ou desuso, geral e contínuo, confirmado pela jurisprudência, permitindo participação direta do povo no progresso jurídico; a admissão da escusa de sua ignorância por parte de indivíduos rústicos, habitando longe dos núcleos urbanos; a uniformização da jurisprudência através de Resoluções do Supremo Tribunal Federal; a interpretação na base do bem comum, da justiça social e da eqüidade; a condenação do abuso do direito, quer por ação, quer por omissão, não sendo mais "protegido o direito que fôr ou dejxar de ser exercido, em prejuízo do próximo ou de modo egoista, excessivo ou antisocial" (art. 11). 
Em matéria de direito internacional privado o Anteprojeto deixou de lado os critérios simplistas e superados, de lei nacional ou de lei de domicílio, sistemàticamente para grandes grupos de relações jurídicas; disciplinou-as em categorias mais restritas, buscando outros critérios menos lógicos porém mais justos, eqüitativos, práticos e efetivos, da lei da residência habitual, da lei da situação principalmente dos imóveis, regendo pela lei brasileira a sucessão quanto aos aqui situados, da lei do lugar da execução, da lei mais favorável aos atos, ao filho, ao incapaz, ao alimentando, etc., da lei brasileira em defesa dos interêsses do pais e dos brasileiros etc..

A propósito do direito intertemporal o Anteprojeto estava limitado pelo preceito constitucional, que é a forma brasileira da não retroatividade, do respeito ao direito adquirido, ao ato jurídico perfeito e à coisa julgada. Mas regulou os problemas dos atos complexos, iniciados e não completados, dos prazos em curso, etc.. Finalmente sôbre a computação dos prazos uniformizou critérios tradicionais, que estavam, às vêzes, tumultuados, em diversas leis civis, processuais, administrativas.

Agradeço profundamente a Deus o me ter permitido oferecer ao meu país, e, particularmente, aos meus colegas, juristas brasileiros de tôdas as categorias, e aos meus alunos, de tôdas as épocas, essa modesta contribuição buscando, na medida de minhas fôrças, o progresso do direito pátrio.

Espero e agradeço a colaboração de todos os brasileiros, juristas ou não, para o aperfeiçoamento do Anteprojeto desta Lei Geral, que a todos interessa.

Termino, pois, pedindo ao insigne Freitas para a presente Lei, a democrática divisa de seu Esbôço: "quod omnes tangit, ab omnibus debet approbari". 


\section{Denominação da nova lei.}

1. O Projeto abandona o título antigamente adotado, no assunto, Introdução (1916) ou Lei de Introdução (1942) do Código Civil, que não corresponde, em absoluto, à realidade, pois os respectivos textos se referem, indiscutivelmente à aplicação de tôdas as leis e não apenas a uma lei, à que promulga o Código Civil.

Fôra influência germânica no Projeto Beviláqua, com a simples tradução do título: Einführungsgesetze zum Burgerlichen Gesetzbuch von 18 August 1896, Lei de Introdução ao Código Civil, de 18 de agôsto de 1896 da Alemanha, lei pois, restrita àquele Código Civil, quer no seu título; quer nos seus textos que, em grande maioria se referem, nominalmente, ao mesmo Código.

Apresentou orientação singular, diversa da seguida noutros países e no Brasil.

O Código Napoleão, 1804, abriu-se com um Titre Preliminaire, assim denominado: De la publication, des effets et de l'application des lois en général e não se refere ao Código Civil mas às leis em geral. Essa diretriz foi a seguida no Século XIX nos Códigos dos países que o adotaram ou seguiram ou sofreram influência daquele Código, salvo a Holanda, assim: Luxemburgo e Cantão de Genebra, 1804, Bélgica, 1807, Polônia, 1808, Luisiânia, 1808-1825, Grão Ducado de Baden, 1809, Cantão de Vaud, 1819, Haiti 1825, Bolívia, 1831, Sardenha, 1837, Costa Rica, 1841 e 1887, República Dominicana, 1845, Ilhas Jonias, 1841, Estados D'Este, 1851, Cantão de Valois, 1852, Cantão de Neuchâtel, 1854, Rumânia, 1864, Mônaco, 1881, Espanha, 1889. . Confirmando o Título Preliminar com outra expressão, De la Ley y sus Efectos, con las reglas generales de su aplicación, aparece o Código da Venezuela de 1862 até o último, de 1942, repetido pelo do México de 1870, de Honduras de 1898 , de Porto-Rico, 1902 e 1930; prolixamente, do Baixo-Canadá (Quebec), de 1865, De la promulgation, de la Distribution, 
de l'Effet, de l' Application, de l'Interpretation et de l'Execution de Lois en Général, e de maneira reduzida, um dos mais recentes Códigos, o das Filipinas, de 1951, Effect and Application of Laws.

O Código do Chile, 1855, mantendo o Título Preliminar distribue-o em seis $\S \S$ sôbre a Lei, Promulgação, Efeitos, Interpretação, Definição de vocábulos e Derrogação, critério adotado em alguns dos Códigos que o seguiram no Pacífico e nos Andes, Cundinamarca de 1849, Equador e Salvador, de 1860, Colômbia de 1873, Honduras de 1906.

Ainda com um "Título Preliminar" mas de modo sintético encontramos o Código Civil do Peru de 1851, De las Leyes en General, seguida pelo da Guatemala, 1877; essa fórmula seria ainda abreviada num título, do Código do Uruguai, 1868, De Las Leyes, adotado no da Argentina, 1869, e no do Montenegro, 1881.

O Código da Áustria de 1811 abria-se com uma Introdução Das Leis em Geral, adotada pelo da Sérvia, de 1844, mui diverso, pois, da Lei de Introdução do Código Civil alemão.

Já o Código Civil da Itália de 1865 destacara a matéria co próprio Código, não fazendo dela um título do mesmo mas dando-lhe autonomia e precedência, promulgados que foram: "Il Codice Civile e le Disposizione sul la publicazione, interpretazione ed applicazione delle Leggi in generale che lo precedono", Decreto 2358, de 25/6/1865, diretriz mantida no novo Código, de 1942, Decreto Real n. ${ }^{\circ} 242$, de 16/5/1942.

No sentido, assim, da autonomia completa da matéria, fôra a Lei da Holanda, de 15 de maio de 1829, contendo Disposições Gerais sôbre a legislação do Reino, que entrou em vigor em 1838 com os novos Códigos Civil e Comercial. Também o Japão, ao adotar o seu Código Civil, Lei n. ${ }^{\circ}$ 9, de 1898, promulgou na mesma data, uma $L e i$, autônoma, Lei n. $^{\circ}$ 10, chamada Horei, concernente à Aplicação das Leis. Afinal, o Estado da Cidade do Vaticano com a Lei 
sôbre as Fontes do Direito, de 8 de junho de 1929. E o mais recente dos Códigos Civis, o da Etiópia, de 1960, que teve como principal redator o Professor René David, deixou tôda a matéria para uma lei autônoma, especial, não apresentando mesmo qualquer título preliminar ou introdução.

Exclusivamente sôbre Direito Internacional Privado citam-se as leis autônomas, Federal Suíça, de 25 de junho de 1891, da China, de 5 de agôsto de 1918, Fa lu che yong T'ao Li, da Polônia, de 2 de agôsto de 1926, do Sião de 10 de março de 1939 Lei sôbre Conflito de Leis, do Uruguai, 10084, de 3 de dezembro de 1941 (lei a ser incluída no final do Código), da Tcheco-Eslováquia, de 11 de março de 1948.

No trabalho de reforma do Código Civil francês, 194519500, uma Sub-Comissão, mantendo a tradição do Código de 1804, aprovou esquema não dum Título mas dum Livro Preliminar, com o Título I, Das Fontes do Direito, dos Conflitos de Leis no Tempo, Capítulo 1, Das Fontes abrangendo: Teoria do Direito: Publicação, abrogação, Disposições Regulamentares, Costume e Função do Juiz na ausência de lei e do costume e o Capítulo 2, os referidos Conflitos. Em separado aprovou-se um Projeto de Lei em matéria de Direito Internacional Privado, sôbre Condição de Estrangeiro e os diversos tipos de Conflitos, de Leis, de Autoridades e de Jurisdições, com 114 artigos.

O Código Civil do Egito, 1948, abre-se com um grande Capítulo Preliminar, Disposições Gerais, Seção I, Leis e sua aplicação, 1, Leis e Decretos, 2, Aplicação das Leis, Conflitos de Leis no Tempo e Conflitos das Leis no Espaço. Já no da Grécia, de 1940-1946, figura um Livro I, Princípios Gerais, Seção I, as regras de direito em geral e Seção II, Direito Internacional Privado.

Nas Bases da Legislação Civil da União Soviética e Repúblicas Federadas, tomou-se diretriz singular antes seguida pelo Código Civil da Suíça de 1907 (e o da Turquia de 1927, que o adotou) de tratar de Direito Internacional Privado no fim do Código e, assim, a U.R.s.s. o fêz na Seção VII 
daquelas Bases com o Título da Capacidade Jurídica dos Estrangeiros e Condições de aplicação das leis civis dos paises estrangeiros.

Finalmente na Polônia foi publicado, em 1961, para receber sugestões, um Projeto de Lei de Direito Internacional Privado, com 30 artigos e na Venezuela, em 1963, um Projeto de Lei de Normas de Direito Itnernacional Privado.

Sente-se nessa exposição histórica e comparativa que as matérias, objeto do presente Projeto, representando disposições gérais sôbre a Aplicação das Leis devem estar fora do Código Civil, constituem assunto autônomo, qual vem sendo adotado nas legislações de vários povos, mantendo-se só por tradição ressequida em formas sem a mínima expressão real, Título ou Capítulo ou Lei com as denominaçổes: Preliminar, Introdução, Lei de Introdução.

2. No Brasil, Freitas abrira o Esbôço, 1860, com um Título Preliminar, Do Lugar e do 'Tempo, mas a seguir, quando pleiteou a sua grande reforma, 1867, propôs ao lado do Código Civil unificado, civil e comercial, um Código Geral que "dominará a legislação inteira", abrangendo "matérias superiores a todos os ramos da legislação", "sôbre as leis em geral, sua publicação e aplicação", "regras de interpretação", "providências sôbre computação de prazos".

$\mathrm{E}$ exclamou com tôda procedência: "E se tais disposições são extensivas às leis de tôdas as espécies como negar que estão impròpriamente em um dos códigos?"

Não há, pois, como incluí-los nem no corpo, nem como preliminar ou introdução de um dos Códigos.

Ou outros Projetos, Nabuco, 1873, e Felício dos Santos 1884, mantiveram Título Preliminar, o segundo nestes têrmos: Da publicação, efeitos e aplicação das leis em geral, dividido o Capítulo II, dos Efeitos, em Seção I. quanto ao tempo, e Seção II, ... quanto ao espaço, o de Coelho RoDrigues optou por "Lei Preliminar do Código Civil Da Publicação da lei e dos seus efeitos quanto ao tempo, ao espaço e ao seu objeto", que não incorporava ao Código 
mas dêle excluia no exemplo da Holanda e da Itália ( $E x$ posição de Motivos, p. 10 e 47), e, finalmente, o de Clovis Bevilaqua, adotando a técnica alemã, da Lei de Introdução ao Código Civil, logo combatida por Duarte de Azevedo, Coelho Rodrigues e outros (Trab. Com. Espec., II/13 e 258), reconhecendo Bevilaqua, em defesa, que "êsse título preliminar ou lei de introdução não é parte integrante do Código" (Trab. Com. Espec., II/127).

Ainda na Câmara e no Senado continuaram as críticas àquele ponto de vista. Assim no parecer da Comissão Especial da Câmara, de 1901, o saudoso professor Azevedo MARQues se referia ao assunto como "uma lei especial fora do corpo do Código" (Cód. Civ. Br. - Trab. Elaboração, III/761); e na discussão ali dizia Andrade Figueira: "em lei especial e não no Código", "convém separar do Código tudo que não seja privativo" (Trab. Com. Espec. IV, 6 e 21) e no parecer final, de 1902, Sylvio Romero falava sôbre uma Lei Preliminar ao Código, "alheia ao contexto intrínseco do Código" (Trab. Com. Espec., III, 31). Ruy Barbosa, no Senado, após mostrar que a Lei de Introdução ao Cód. Civil da Alemanha se refere sempre a "Êste Código", o que não era possivel nos textos propostos, fulminou-a com estas palavras: "Tão longe está ela, naquele país, de constituir com o Código um só corpo, que teve promulgação diversa apesar de se fazer na mesma data. E tão pouca significação, por êsse lado, tem o seu nome de lei introdutória ou lei de introdução, que em vez de preceder o Código Civil, lhe é subseqüente". E a Comissão Especial do Senado, em sessão de $10^{\circ}$ de setembro, 1912, aceitando tal observação, mandou colocar o título inicial "Código Civil", após os textos da Lei Preliminar. A emenda ficou sem objeto pela aprovação doutra, que foi adotada em sessão de 16 de dezembro de 1912 (Anaes Senado, p. 51), de Feliciano Pena, substituindo-se "Lei Preliminar" por Introdução".

Mas a doutrina brasileira voltou a FreItas, no sentido da autonomia da matéria, a ser objeto de lei própria, a parte do Código Civil. Assim desde logo o próprio Clovis Bevi- 
laqua (Cód. Civil Com, I, 86), seguido por Paulo de LaCERDA ("não faz parte, pròpriamente, do Código", Manual do Código Civil, I, p. 1. a, p. 57), Matos Peixoto (Rev. For. 77, p. 5 е ss.) e pelos próprios autores, Ministros Овоzімво Nonato, Philadelpho Azevedo e Hahnemann Gummarães, da atual Lei de Introdução do Código Civil, que, aliás, no entender da Comissão, "não deve continuar a fazer parte do mesmo Código, com o qual não guarda ligação necessária. Além disso, entre as matérias de que se ocupa a chamada Lei de Introdução, está a da aplicação das leis no espaço, oferecendo perspectivas de desenvolvimento ulteriores, independentemente das transformações nos institutos civis, o que aconselha dela se forme lei especial, como sugeria Demogue, a propósito dos trabalhos de reforma do Código Civil Argentino, em artigo publicado na contribuição da Universidade de La Plata àquela reforma" (Arq. Min. Just. Neg. In., I, p. 46 e 7).

$\mathrm{E}$, afinal, no mesmo sentido, os principais comentadores da atual Lei de Introdução (Serpa Lopes, I, n. 1; Eduardo Espínola e Eduardo Espínola Filho, I, p. 10: "nenhuma regra existe para considerar-se uma Lei de Introdução ao Código Civil, quando é verdadeiramente, o diploma de aplicação, no tempo e no espaço, de tôdas as leis brasileiras"; Oscar Tenório, n. ${ }^{\circ}$; ; Wilson Batalha, v. I, n. ${ }^{\circ} 6$, etc.). Escrevemos, mesmo, a respeito: "Terá de ser um diploma autônomo e amplo, uma Lei Geral, independente, sôbre as Fontes do Direito, com as respectivas normas básicas, de grande relevância especialmente num Estado de organização federativa, qual o Brasil, versando a hierarquia, vigência e territorialidade, hermenêutica, direito internacional privado, direito intertemporal..." (A Lei de Introdução ao Código Civil e sua Reforma, Congresso Nacional de Direito de Fortaleza, em fascículo, 1959, e em tôdas as revistas de direito do Brasil, de 1959 a 1960). José Frederico MarQues mostra como princípios da atual Lei de Introdução aplicam-se até à lei penal (Dir. Penal, I, p. 147). 
Doutra parte a distribuição das matérias do direito civil no currículo das Faculdades de Direito exclui todos os assuntos versados na Introdução, começando pela Parte Geral do Código (Regim. Fac. Nac. Direito, art. $5^{\circ}$ ) e os últimos livros do direito civil, dos Professôres Orlando Gomes e Washinton de Barros Monteiro procedem do mesmo modo.

Por tudo isto preferimos denominar o Projeto: Lei Gerai de Aplicação das Normas Jurídicas, abrangendo, com grande desenvolvimento, os assuntos que vem sendo disciplinados na Introdução, 1916, e na atual Lei de Introdução, 1942, do Código Civil e outros anunciados.

Era aliás a forma adotada na primitiva distribuição das matérias dos Códigos e leis ora em reforma.

3. O Anteprojeto de Lei Geral, apresentado, se divide em seis Capítulos, I, Disposições Gerais sôbre a Lei e outras normas jurídicas (Promulgação, Publicação, Vigência espacial, pessoal e temporal, Revogação, Conhecimento da lei e escusa, Fontes Subsidiárias, Hierarquia, Interpretação, Condenação do Abuso de Direito e Ordem Pública); II, Disposiçôes sôbre Tratados e Convenções Internacionais e Decretos e Regulamentos; III, Disposições sôbre Direito Internacional Privado; IV, Disposições sôbre Direito Intertemporal; V, Disposições sôbre Computação de Prasos; VI, Disposições Finais. 